\title{
Conjunctival Cyst
}

National Cancer Institute

\section{Source}

National Cancer Institute. Conjunctival Cyst. NCI Thesaurus. Code C3650.

Abnormal fluid filled sac within the conjunctiva. 